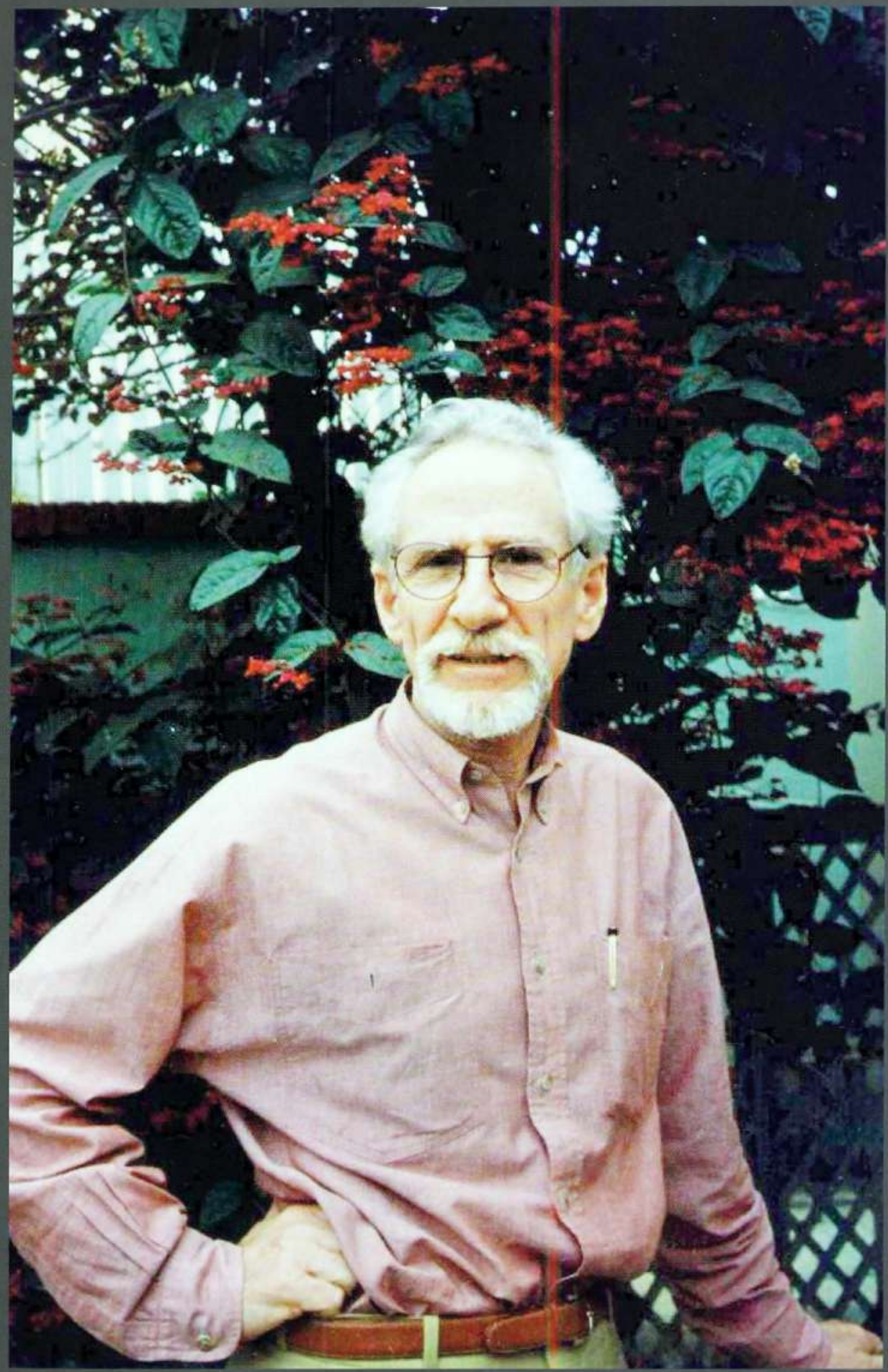




\section{Francisco Stastny \\ (Praga 1933 - Lima 2013)}

Sara Acevedo

A Francisco Stastny se le recuerda e identifica como el acucioso investigador del arte colonial peruano, pero también por su preocupación sobre el papel de los museos en una realidad como la nuestra y por la defensa de los bienes culturales y artísticos. Indicaba sobre ello que es una labor que ninguna nación puede dejar al azar en nuestros días ${ }^{1}$.

Mi relación con él data desde la universidad. Fui su alumna en los cursos de Arte Colonial y Republicano del Perú y Latinoamérica, de Arte Popular y de Museología, en la Escuela de Arte de la Facultad de Letras. Es, en ese tiempo cuando me convoca a trabajar con él en el Museo de Arte y de Historia de la Universidad ${ }^{2}$. Museo que había fundado con mucho entusiasmo en la vieja Casona sanmarquina en marzo de 1970, encargándome la conservaduría de la sección de Arte Popular cuyas importantes colecciones eran un mundo por atender e investigar y que nos motivó hacia una dedicación especial posterior. También se nos encargó el área educativa en la que el museo de San Marcos desarrollaba una pionera e importante labor de proyección a través de los talleres de arte para niños y jóvenes.

Por tal razón deseo expresar mi reconocimiento por lo aprendido en sus clases, por las experiencias, la disciplina y la seriedad compartidas en el trabajo diario. Aspectos que luego me permitieron asimilar las responsabilidades requeridas en el campo de los museos. Ellas me posibilitaron asumir, a su jubilación en la universidad, su curso de Arte Popular y luego a dirigir el Museo Nacional de la Cultura Peruana. Pero también quisiera destacar la confianza en los encargos, su amistad, y su amplitud en el diálogo donde mostraba una atenta y particular intuición. Conversaciones muchas veces sostenidas en el ámbito familiar, y con su entrañable compañero y amigo Aníbal Quijano, que siempre recordaremos.

Un aspecto inédito de su pronta incursión en el ámbito de la cultura peruana lo pudimos observar cuando reuníamos y ordenábamos sus textos para elaborar su bio-bibliografía ${ }^{3}$ con la expectativa de que se pudieran publicar ${ }^{4}$. Fueron las notas que escribió para la revista del Colegio Anglo Peruano de Lima, hoy San Andrés, cuando cursaba los años finales de la secundaria. En ellas mostraba lo que sería más adelante una dedicada vocación y la forma de exponer sus ideas a través de un discurso claro y conciso. Tal inquietud la fue modelando desde la Universidad Nacional Mayor de San Marcos con distinguidos maestros y sus compañeros. Pero también con sus estudios de perfeccionamiento realizados en Europa, a la que regresaba después de haber salido muy niño con sus padres hacia América.

1 Ossio M., Juan. Patrimonio Cultural del Peru. Balance y Perspectivas. FOMCIENCIAS. Lima, 1986, p.155.

2 Hoy Museo de Arte del Centro Cultural de San Marcos.

3 "Bio-biliografia de Francisco Stastny Mosberg". En Revista del Museo Nacional. T.L: 307-331. Lima, 2010. Ministerio de Cultura - Museo Nacional de la Cultura Peruana.

4 Por gestión de la familia Stastny, el Museo de Arte de Lima y el Instituto Francés de Estudios Andinos, bajo la selección e introducción de Sonia Rose y Juan Carlos Estenssoro, ha publicado, en el presente año, un primer volumen titulado Estudios de Arte Colonial, como parte de la serie Fuentes para la Historia del Arte Peruano. 
En la cátedra, sin mucha retórica, trasmitía con objetividad los temas programados y reflexionaba sobre ellos. Y, entre líneas, abría luces hacia nuevas propuestas e investigaciones por abordar. Sus alumnos estuvimos siempre prestos a captar esas valiosas observaciones y él, a su vez, a escuchar con atención sus dudas y comentarios.

Además de su desempeño en la cátedra, desde el año 1963, donde desarrolló una destacada labor, tuvo otras responsabilidades académicas. Fue Coordinador de la Sección de Arte del antiguo Departamento de Humanidades, miembro del Comité Directivo de la Escuela de Postgrado y de la Comisión de Investigación del Vice Rectorado, y miembro permanente del Instituto de Investigaciones Humanísticas. Participó en la elaboración del Plan de Estudios de la Escuela de Arte, con una orientación renovada, en lo que sería la nueva época de la Facultad de Letras y Ciencias Humanas. Su retiro de la universidad a fines de los años ochenta, no significó un alejamiento total. Siempre estuvo ligado a sus colegas y ex alumnos con quienes compartiría los avatares de la cultura nacional. Y finalmente alentó los estudios de posgrado en historia del arte, cuya materialización constituyó su retorno al alma mater. Su vida estuvo entrañablemente vinculada a la Universidad de San Marcos donde pasó largos años de su vida, formó sendas promociones y desarrolló gran parte de sus investigaciones, recibiendo por ello el reconocimiento de Profesor Emérito (1991) y largos años después (2012), ya en las postrimerías de su vida, la Medalla de la Cultura por su aporte a la cultura y el arte peruano.

Cabe destacar otras acciones desarrolladas en su vida profesional. De regreso al Perú se integró al equipo que participó en la creación del Museo de Arte de Lima, cuya dirección asumió entre los años 1964 y 1969, realizando una clara labor museológica vinculada a la puesta en valor de las artes plásticas nacionales, donde, con el apoyo de la UNESCO, y la consultoría del especialista belga, Paul Coremans, establecería el primer Laboratorio Científico de Conservación del país contribuyendo así a plantear la importancia del tratamiento técnico y científico en la intervención de las obras de arte, y a destacar la valiosa información que de ellas podía obtenerse, para su mejor comprensión e interpretación.

Similar labor docente desarrolló en el Posgrado de Letras de San Marcos, en la Facultad de Arquitectura de la Universidad Nacional de Ingeniería, en la Facultad de Arquitectura del la Universidad Peruana de Ciencias Aplicadas (UPC) y en el Departamento de Historia de la Pontificia Universidad Católica del Perú. Fue así mismo Director Colegiado en el Instituto Superior Tecnológico de Conservación "Yachay Wasi" y se desempeñó como profesor visitante y conferencista en las Universidades de Yale, Londres, Pittsburg, París III, México, Sao Paulo y Caracas.

Sus pesquisas merecieron el apoyo de la UNESCO y de las Fundaciones Guggenheim, Gulkenkian, Ford y Paul Getty, que culminaron con significativos aportes a la especialidad exponiéndose en numerosos Congresos y reuniones académicas internacionales sobre el arte americano.

Es dable destacar su activa participación en el campo de la cultura y en la protección del patrimonio cultural a fin de prevenir su tráfico ilícito, por lo cual expresaba una profunda preocupación. Fue miembro del Consejo Nacional de Conservación de Monumentos Históricos y Artísticos y del Consejo General de Cultura del Instituto Nacional de Cultura. Dirigió el programa de creación del Museo de Arte Colonial Pedro de Osma e integró el grupo de expertos de la UNESCO para la creación de la Escuela Latinoamericana de Museología de Bogotá. Condujo el proyecto PEPPAC, Prospección del Patrimonio Cultural Colonial, con el propósito de sistematizar el registro y los inventarios, tan necesarios para salvaguardar el patrimonio nacional; y el PROBAC, Proyecto de Catalogación de los Bienes artísticos del Valle del Colca. Este último de carácter multidisciplinario y descentralizador, realizado por las Universidades de San Marcos y San Agustín de Arequipa, con la participación de docentes y estudiantes en pro del patrimonio regional. Tarea que valdría la pena 
replicar en otras zonas del país, en lo que hoy se conoce como responsabilidad social, pero en el campo de la cultura. Igualmente condujo proyectos de estudio y restauración de series religiosas importantes como la de Santo Domingo de Lima.

Todas estas actividades no fueron mella para que desarrollara pioneras investigaciones sobre diversos aspectos de la historia del arte peruano y americano cuyos alcances han contribuido al esclarecimiento de la producción y la expresión artística en el Perú, así como sus correspondencias sociales e ideológicas. Sus estudios han sido puntos de partida y de encuentro de posteriores proyectos sobre todo aquellos dedicados a la trayectoria, al análisis y a develar los valores culturales y artísticos del arte colonial y el manejo de la simbología andina.

Temas como la obra de los pintores Bitti y Pérez de Alesio tratados en sus tesis de grado, así como las influencias italianas tempranas, la pintura peruana de los siglos XVI y XVII y el uso de los grabados en el arte colonial, fueron de su especial interés. Con igual esmero trató la pintura limeña, las corrientes artísticas internacionales, las obras de artistas europeos en el Perú, la significación de la pintura cusqueña y sobre todo las invenciones iconográficas americanas.

Su preocupación por el aspecto metodológico para emprender el estudio del arte le permitió tratar temas de carácter iconológico más complejos, como los relacionados con las composiciones doctrinales, los programas desarrollados por las órdenes religiosas y el mundo colonial, y en especial el arte de la nobleza inca en su trasfondo histórico.

Dedicó algunos trabajos a los pintores de la república como Pancho Fierro y a su genuina exploración de la realidad americana, o Francisco Laso reconociendo en su obra el compromiso confrontacional entre la realidad americana y la cultura occidental en su camino hacia la búsqueda de la identidad propia. No olvidó al emblemático José Sabogal en el siglo XX y a sus fuentes indigenistas. Propugnó la necesidad de precisar ciertas nociones básicas del arte peruano en el marco de los conceptos generales del arte y, a su vez de puntualizar los del espacio andino. Reclamó así mismo un mayor interés por el estudio las artes decorativas peruanas.

Otro de los temas que emprendió, desde el punto de vista teórico, fue el del arte popular peruano como ejemplo de fusión, de mestizaje, de supervivencias antiguas, de continuidad de la sensibilidad aborigen y de la incorporación de motivos y formas occidentales que es necesario leer a través del proceso de disyunción entre la forma y el contenido.

Sus trabajos destacan por la brevedad y claridad del discurso expositivo, por la rigurosidad en la metodología y el manejo de las fuentes, así como por los aportes significativos de sus contenidos, constituyéndose en indispensables lugares de consulta para el estudio del arte peruano y latinoamericano tanto en el ámbito nacional como internacional. Es así que integra los Consejos Asesores de los "Anales del Instituto de Investigaciones Estéticas de la Universidad Autónoma de México" y de los "Anales del Instituto de Arte Americano" de la Universidad de Buenos Aires, revistas de reconocido prestigio académico de la región.

Debido a su constancia y vena investigativa en la historia del arte peruano fue incorporado como Miembro de número de la Academia Nacional de Historia del Perú en el año 2002.

Los momentos compartidos en las aulas, en el museo, en el trabajo de campo pero también en la vida cotidiana nos acercó a su personalidad aparentemente seria y estricta que poco dejaba traslucir su honda sensibilidad, no sólo en lo artístico sino también ante la belleza y el misterio de la naturaleza que descubría con detenimiento y encanto. • 